\title{
Experimental Investigation of Closed Porosity of Inorganic Solidified Foam Designed to Prevent Coal Fires
}

\author{
Yi Lu' ${ }^{1,2}$ and Botao Qin ${ }^{1,2}$ \\ ${ }^{1}$ State Key Laboratory of Coal Resources and Mine Safety, China University of Mining and Technology, Xuzhou, Jiangsu 221008, China \\ ${ }^{2}$ School of Safety Engineering, China University of Mining and Technology, Xuzhou, Jiangsu 221116, China \\ Correspondence should be addressed to Botao Qin; qbt2003@163.com
}

Received 10 November 2014; Accepted 14 February 2015

Academic Editor: Jui-Yang Lai

Copyright (C) 2015 Y. Lu and B. Qin. This is an open access article distributed under the Creative Commons Attribution License, which permits unrestricted use, distribution, and reproduction in any medium, provided the original work is properly cited.

\begin{abstract}
In order to overcome the deficiency of the existing fire control technology and control coal spontaneous combustion by sealing air leakages in coal mines, inorganic solidified foam (ISF) with high closed porosity was developed. The effect of sodium dodecyl sulfate (SDS) concentration on the porosity of the foams was investigated. The results showed that the optimized closed porosity of the solidified foam was $38.65 \mathrm{wt}$.\% for an SDS concentration of approximately $7.4 \times 10^{-3} \mathrm{~mol} / \mathrm{L}$. Based on observations of the microstructure of the pore walls after solidification, it was inferred that an equilibrium between the hydration process and the drainage process existed. Therefore, the ISF was improved using three different systems. Gelatin can increase the viscosity of the continuous phase to form a viscoelastic film around the air cells, and the SDS + gelatin system can create a mixed surfactant layer at gas/liquid interfaces. The accelerator (AC) accelerates the hydration process and coagulation of the pore walls before the end of drainage. The mixed SDS + gelatin + AC systems produced an ISF with a total porosity of $79.89 \%$ and a closed porosity of $66.89 \%$, which verified the proposed stabilization mechanism.
\end{abstract}

\section{Introduction}

Coal fires are difficult, persistent, and costly problems in various regions and countries such as China, India, the United States, Russia, Australia, and Indonesia, with serious environmental, safety, and economic consequences [1]. It is well known that $75 \%$ of the coal fires occur due to spontaneous combustion of coal. A continuous supply of oxygen arising from air leakage of mining fractures is the basic requirement for spontaneous combustion of coal. In order to overcome the deficiency of the existing fire control technology and control coal spontaneous combustion by sealing air leakages in coal mines, inorganic solidified foam (ISF) was prepared [2]. It consists of fly ash, Portland cement paste, prefabricated foam liquid, and some additives. It is a porous material whose macroscopic properties are strongly related to the microstructure of the foam. For example, air leakage sealing and thermal insulation are governed by the structure of closed or interconnected bubbles because open porosity is in some situations a drawback to good sealing and insulation [3]. Moreover, material durability is strongly affected by this porosity because of fluid and ion transport within the foam slurry [4]. Consequently, to achieve an excellent material, foam porosity must be controlled to obtain disconnected air bubbles within the slurry $[5,6]$.

In our research, there were still many bubbles produced that were more open, exhibiting undefined "holes in holes" [7]. Many factors such as drainage, coarsening, or rupture affect the interconnection between bubbles, mainly during foam generation and solidification [8]. The first step to achieve such a solidified foam is to create one single, closed, and solidified bubble. Then, a prerequisite is the formation of a longstanding stable bubble that will in a second step be solidified via a fly ash and cement hydration reaction, which ideally maintains the geometry, size, and shape of the bubbles of the liquid foam. In this work, the effects of surfactant, foam stabilizer, and setting accelerator on total porosity, open porosity, and closed porosity of ISF were investigated. Furthermore, the dynamic changes of the pore walls during the solidification process were analyzed and the reasons for the existence of holes in the pore walls were explained. 
TABLE 1: Chemical composition of the accelerator.

\begin{tabular}{lccccccc}
\hline Chemical composition & $\mathrm{Na}_{2} \mathrm{CO}_{3}$ & $11 \mathrm{CaO} \cdot 7 \mathrm{Al}_{2} \mathrm{O}_{3} \cdot 3 \mathrm{CaF}_{2}$ & $\mathrm{SiO}_{2}$ & $\left(\mathrm{Al}_{2}, \mathrm{Mg}_{3}\right)\left[\mathrm{Si}_{4} \mathrm{O}_{10}\right][\mathrm{OH}]_{2} \cdot \mathrm{H}_{2} \mathrm{O}$ & $\mathrm{Al}_{2} \mathrm{O}_{3}$ & $\mathrm{Fe}_{2} \mathrm{O}_{3}$ & $\mathrm{CaO}$ \\
\hline Mass fraction (wt.\%) & 11 & 47.5 & 9.5 & 14 & 7 & 3 \\
\hline Molar mass (g/mol) & 106 & 1564 & 60 & 450 & 102 & 160 & 56 \\
\hline
\end{tabular}

\section{Experimental Procedure}

2.1. Raw Materials. The raw materials used in the study included fly ash and Portland cement (Zaoqiang Yiwei Materials Co., Ltd., Zaozhuang, China), sodium dodecyl sulfate (SDS > 95\%), and gelatin (Yitong Chemical Co., Ltd., Dongying, China). SDS and gelatin were used without further purification. The molar mass of SDS in our experiments is $285 \mathrm{~g} / \mathrm{mol}$ and the molar mass of gelatin is $40000 \mathrm{~g} / \mathrm{mol}$. In addition, ethylene vinyl acetate (EVA) (Hongduo Rubber Plastic Products Technology Co., Ltd., Shijiazhuang, China) was used as a binder to avoid cracks during the solidification process [9].

Accelerator: the raw materials for preparing the accelerator included coal gangue, fly ash, limestone, and fluorite, and their main chemical components are silicon dioxide $\left(\mathrm{SiO}_{2}\right)$, aluminium oxide $\left(\mathrm{Al}_{2} \mathrm{O}_{3}\right)$, ferric oxide $\left(\mathrm{Fe}_{2} \mathrm{O}_{3}\right)$, calcium oxide $(\mathrm{CaO})$, magnesium oxide $(\mathrm{MgO})$, sodium oxide $\left(\mathrm{Na}_{2} \mathrm{O}\right)$, calcium fluoride $\left(\mathrm{CaF}_{2}\right)$, calcium chloride $\left(\mathrm{CaCl}_{2}\right)$, and aluminium hydroxide $\left[\mathrm{Al}(\mathrm{OH})_{3}\right]$. The concrete preparation procedures were as follows. First, all raw materials were ground into fine particles; thereafter, the fine particles were dispersed evenly in the water and pretreated at a temperature of $250^{\circ} \mathrm{C}$ and an air pressure of $1 \mathrm{~atm}$. Lastly, the product (main chemical component is $\mathrm{C}_{3} \mathrm{AH}_{6}$ ) from the pretreatment procedure was calcined for $1-2 \mathrm{~h}$ under the temperature of $850^{\circ} \mathrm{C}-1000^{\circ} \mathrm{C}$ followed by the grinding process until the specific area of ultimate product comes to $500-700 \mathrm{~m}^{2} / \mathrm{kg}$. The chemical reaction equation utilized during the preparation procedures of calcium fluoroaluminate $\left(\mathrm{C}_{11} \mathrm{~A}_{7} \mathrm{CaF}_{2}\right)$ is shown by the following equations. The chemical composition of the accelerator is shown in Table 1. The molar mass of AC can be calculated as $840 \mathrm{~g} / \mathrm{mol}$ based on the molar masses of chemical compositions:

$$
\begin{gathered}
\mathrm{C}_{3} \mathrm{AH}_{6}+\mathrm{CaF}_{2} \stackrel{850-1000^{\circ} \mathrm{C}}{\longrightarrow} \mathrm{C}_{11} \mathrm{~A}_{7} \mathrm{CaF}_{2}+\mathrm{CaO}+\mathrm{H} \\
\mathrm{Al}_{2} \mathrm{O}_{3}+\mathrm{CaO}+\mathrm{CaF}_{2} \longrightarrow \mathrm{C}_{11} \mathrm{~A}_{7} \mathrm{CaF}_{2}
\end{gathered}
$$

2.2. Preparation of Solidified Foam. The suspension was prepared by first adding $35 \mathrm{wt} \%$ fly ash and $20 \mathrm{wt} . \%$ cement to an aqueous solution containing EVA ( 2 wt.\% to fly ash and cement), and this was then mixed. Different aqueous foams were generated based on diluents of SDS and SDS + gelatin using a self-made foam generator. Then, high-pressure air was pumped into the foam generator and aqueous foam was produced. The next procedure was to mix the composite slurry with the aqueous foam in a self-made mixer with some accelerators added. In our experiments, the density of the foam slurry is $1 \mathrm{~g} / \mathrm{mL}$.
2.3. Measurement of Surface Tension and the Critical Micelle Concentration (CMC). Surface tension was measured with an automatic surface tension meter (CBVP-Z, Kyowa Interface Science Co., Ltd., Japan) using the Wilhelmy plate method with an accuracy of $\pm 0.2 \mathrm{mN} / \mathrm{m}$. Calibration was carried out with pure water and ethanol. Measurements were conducted at $27^{\circ} \mathrm{C}$ with a measuring time of $10 \mathrm{~min}$ to allow equilibrium to be achieved. All measurements were conducted at least three times, and the average values were calculated. The $\mathrm{CMC}$ was determined from the surface tension versus log concentration curves, corresponding to the inflection point on the curves. The CMC value obtained was about $7.4 \times$ $10^{-3} \mathrm{~mol} / \mathrm{L}$.

2.4. Porosity Tests. The total porosity $\left(\varepsilon_{t}\right)$ of the solidified foam was obtained by the bulk density $\left(\rho_{b}\right)$ and true density $\left(\rho_{t}\right)$, measured according to the GBT 208-1994 standard [10]. The total porosity can be calculated as follows: $\varepsilon_{t}=1-\rho_{b} / \rho_{t}$. Open porosity $\left(\varepsilon_{0}\right)$ was measured by Archimedes' principle, as shown in Figure 1 . Thus, the closed porosity $\left(\varepsilon_{c}\right)$ was expressed as follows: $\varepsilon_{c}=\varepsilon_{t}-\varepsilon_{0}$.

2.5. Microscopy and Measurement of Bubble-Size Distribution. The fracture surface of samples $(10 \times 10 \times 10 \mathrm{~cm})$ was observed by a digital polarizing microscope (DVET-U, Chongqing Optec Instrument Co., Ltd., China) equipped with morphological analysis software, which was used to measure the average size and size distribution of the bubbles. The average diameters and average size distributions were calculated. The microstructure of the pore walls was investigated using scanning electron microscopy (Quanta TM 250 SEM system, FEI Company, USA) with the size of the test specimen being $10 \times 10 \times 10 \mathrm{~mm}$.

\section{Results and Discussion}

3.1. Surfactant Concentration. The foam drainage equation depends on the mobility of the liquid/gas interface and thus on the choice of surfactant. The surfactant is a key factor in the type of bubbles generated. As we know, the CMC is an important parameter for a surfactant since at this concentration the surfactant will start to aggregate and form micelles. Thus, the CMC is defined as the maximum solubility of a monomer in a particular solution. Since the physicochemical properties of a surfactant vary markedly above and below the CMC, the influence of the surfactant on microbubble properties may differ above and below the CMC [11]. From the measurement of surface tension and the CMC, the CMC of SDS in our experiment was about $7.4 \times 10^{-3} \mathrm{~mol} / \mathrm{L}$. Therefore, SDSs with different concentrations from $3.2 \times 10^{-3}$ to $11.6 \times 10^{-3} \mathrm{~mol} / \mathrm{L}$ (below and approximately above the CMC) were used to 


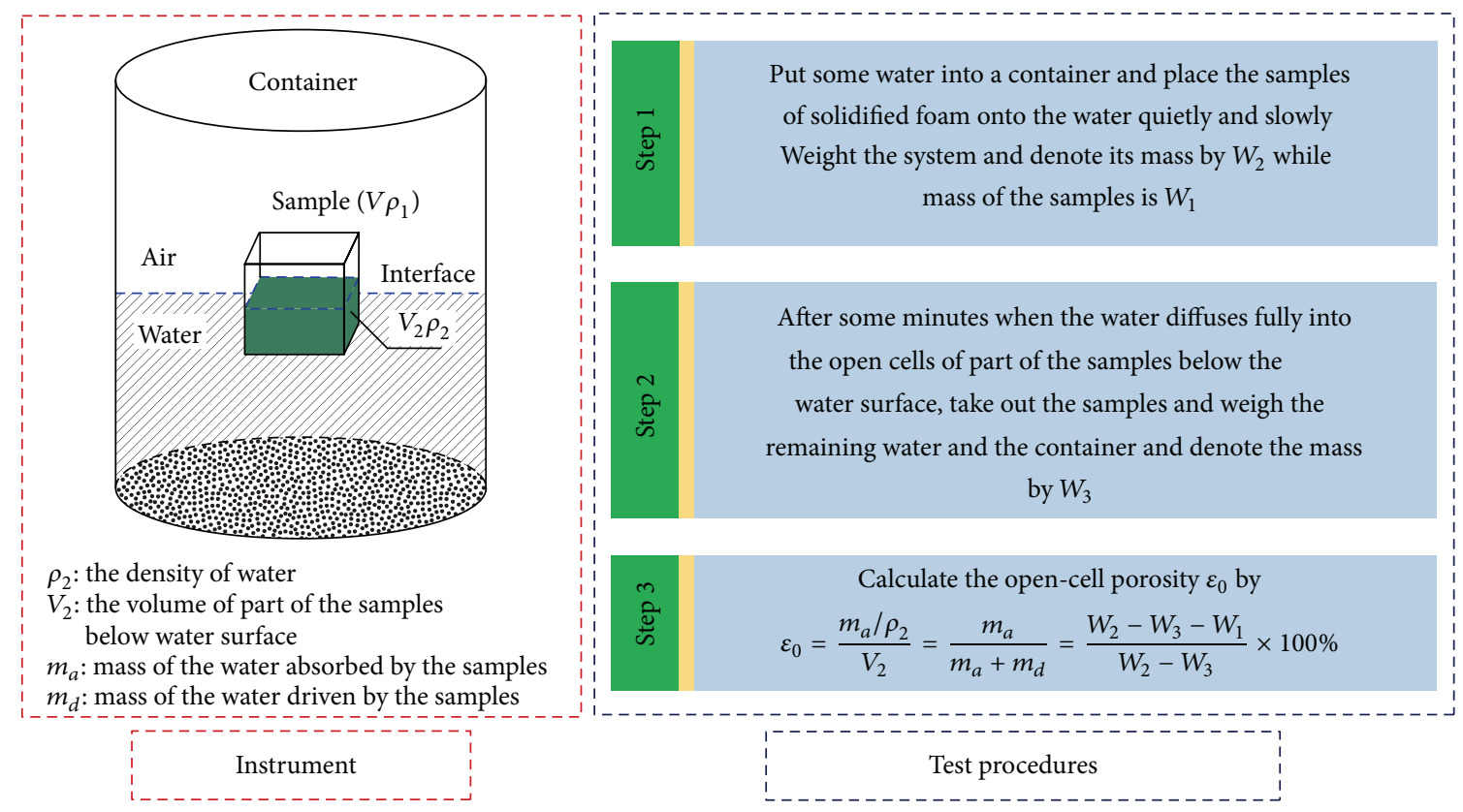

Figure 1: Test method of open porosity.

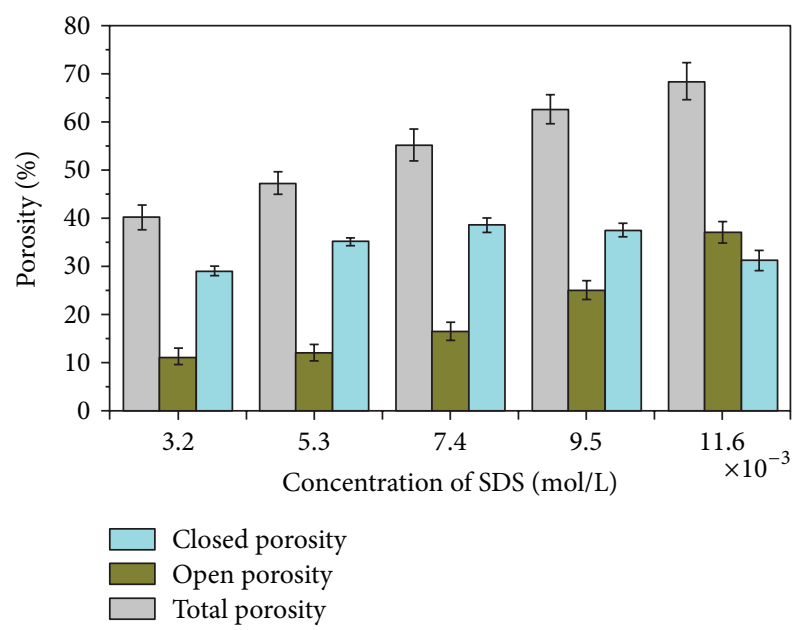

FIGURE 2: Effects of SDS on porosity of ISF.

investigate the porosity changes. The porosities of the ISF varied with SDS concentration, as shown in Figure 2. As the SDS concentration increased from $3.2 \times 10^{-3}$ to $11.6 \times$ $10^{-3} \mathrm{~mol} / \mathrm{L}$, the total porosity and the open porosity tended to slightly increase. This may be attributed to the foam stability of the individual SDS system having a short time span in spite of its excellent foaming ability. As the concentration of SDS increased from $3.2 \times 10^{-3}$ to $7.4 \times 10^{-3} \mathrm{~mol} / \mathrm{L}$, the closed porosity of solidified foams also increased, reaching a maximum of $38.65 \%$ at $7.4 \times 10^{-3} \mathrm{~mol} / \mathrm{L}$ of SDS concentration.

To better understand the reason for the porosity changes as a function of the SDS concentration, some samples with different SDS concentrations were observed by a digital polarizing microscope equipped with morphological analysis software. Figure 3(a) shows the photograph of ISF made from the SDS-stabilized system. The ISF had a length of $10 \mathrm{~cm}$, a width of $10 \mathrm{~cm}$, and a height of $10 \mathrm{~cm}$. The micrographs of the ISF with different SDS concentration systems are presented in Figures 3(b)-3(e). Figure 4 shows the size distributions of bubbles prepared with SDS concentrations of $3.2 \times 10^{-3} \mathrm{~mol} / \mathrm{L}$ and $5.3 \times 10^{-3} \mathrm{~mol} / \mathrm{L}$ (below the CMC), $7.4 \times 10^{-3} \mathrm{~mol} / \mathrm{L}$ (approximately equal to the CMC), and $9.5 \times 10^{-3} \mathrm{~mol} / \mathrm{L}$ (above the CMC). The foam structure of the $3.2 \times 10^{-3} \mathrm{~mol} / \mathrm{L}$ SDS foamed and stabilized system was a small number of well-developed closed pores, and the bubble diameters were $250-300 \mu \mathrm{m}$ with a volume frequency of $25 \%$. The instable foam collapsed, dramatically decreasing the foam amount, as shown in Figure 3(b). At low ionic surfactant (SDS) concentrations, complexes are formed via electrostatic interactions, leading to more hydrophobic entities of higher surface activity. With increasing SDS concentration, hydrophobic interaction became more significant, resulting in less surface activity. When the SDS concentration gradually increased, the foaming ability obviously improved and the foam consequently obtained more pores after solidification (Figures 3(c) and 3(d)). Below the CMC, a leftward shift in the size distribution was observed, as shown in Figure 4. As the SDS concentration increased from $5.3 \times 10^{-3} \mathrm{~mol} / \mathrm{L}$ to $7.4 \times 10^{-3} \mathrm{~mol} / \mathrm{L}$, the bubble diameters were $300-350 \mu \mathrm{m}$ with a volume frequency of $28 \%$ and $350-400 \mu \mathrm{m}$ with a volume frequency of $41 \%$. Above the CMC, there was almost no big change in the size distribution as the SDS concentration was varied. As the SDS concentration increased from $7.4 \times$ $10^{-3} \mathrm{~mol} / \mathrm{L}$ to $9.5 \times 10^{-3} \mathrm{~mol} / \mathrm{L}$, the bubble diameters were $350-400 \mu \mathrm{m}$ and the volume frequency decreased from $41 \%$ to $33 \%$, respectively.

Moreover, around the CMC, it could be clearly seen that these pores were still partly closed, which was attributed to 


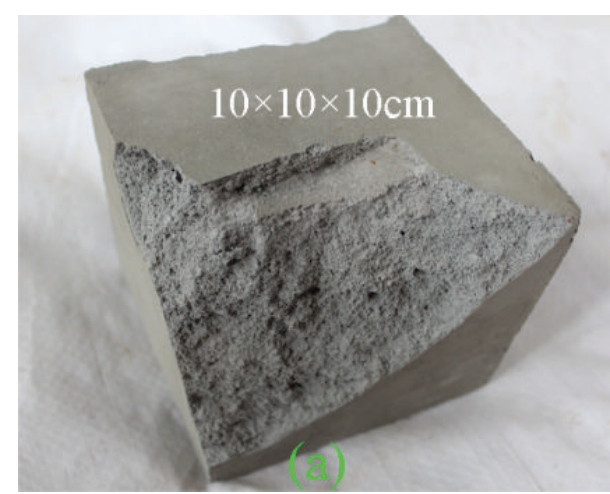

(a)

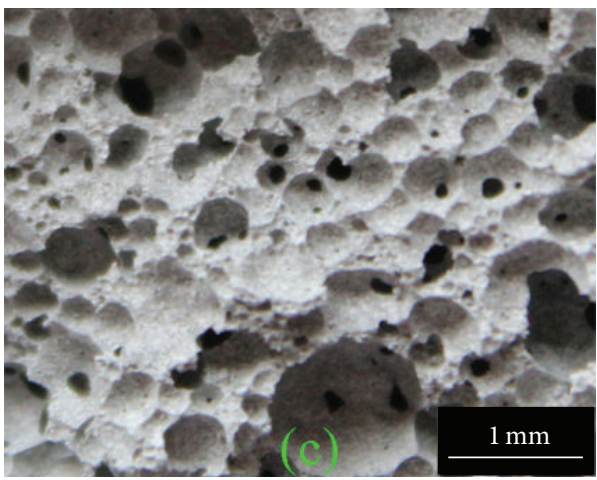

(c)

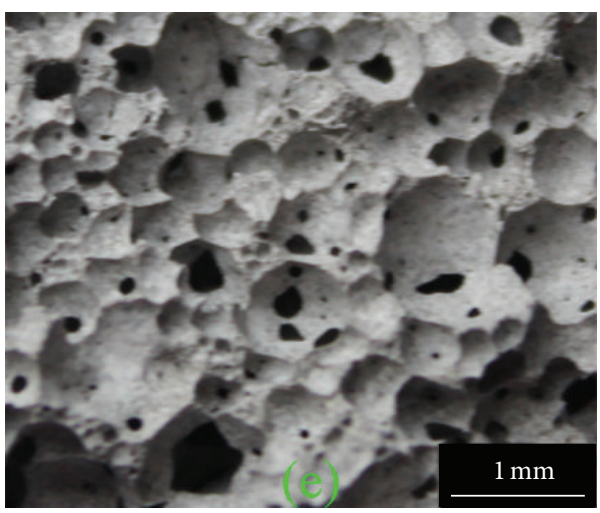

(e)

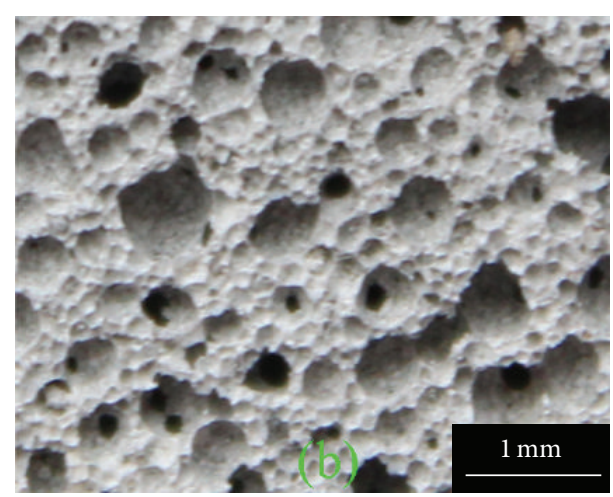

(b)

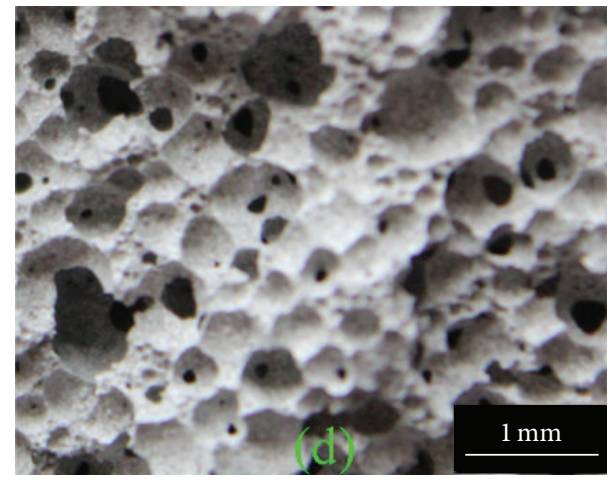

(d)

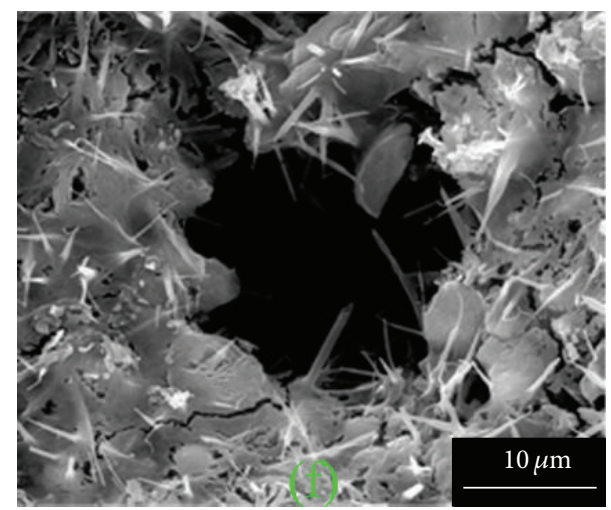

(f)

Figure 3: Photograph and micrographs of ISF based on different SDS concentrations: (a) the $10 \times 10 \times 10 \mathrm{~cm}$ sample, those with (b) $3.2 \times$ $10^{-3} \mathrm{~mol} / \mathrm{L}$, (c) $5.3 \times 10^{-3} \mathrm{~mol} / \mathrm{L}$, (d) $7.4 \times 10^{-3} \mathrm{~mol} / \mathrm{L}$, and (e) $9.5 \times 10^{-3} \mathrm{~mol} / \mathrm{L} \mathrm{SDS}$, and (f) the hydration products near the hole on the pore walls.

the gravitational drainage. The mean pore sizes began to increase and the space between the pores (cell wall thickness) began to decrease. When the SDS concentration reached $11.6 \times 10^{-3} \mathrm{~mol} / \mathrm{L}$, the well-developed open pores, which were interconnected through windows in many directions, were obtained (Figure 3(e)). This indicated that the closed pores gradually transformed into open pores [12]. In the individual SDS-stabilized system, the SDS molecules would adsorb at the interface of the bubbles to decrease the surface tension and the decrease of surface tension would facilitate the foam stabilization. However, these molecules could not completely avoid bubble growth and coalescence because of their low adsorption energy. So, when the foam was stabilized by individual SDS surfactant, the foam was not stable, and consequently the pores were coarse and significant coalescence occurred after solidification.

3.2. Stabilization Mechanism of the Pore Wall. During the SDS foaming and stabilization, a thin water film partitioned the bubbles and three films intersected to form a Plateau border. Fly ash and cement particles could flow through this water network. The bubbles evolve over time by gravitational 


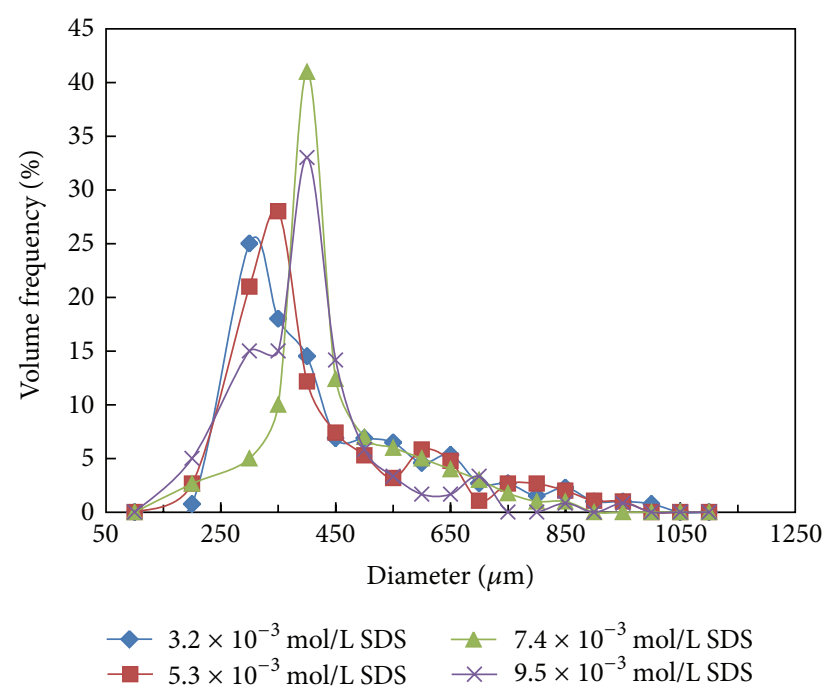

FIGURE 4: Effect of SDS concentration on bubble-size distribution.

drainage, coarsening, and film rupture. Despite the fact that the observation of this time evolution is quite easy, many questions remain unsolved on the mechanisms of these instabilities, and still today no clear picture emerges about what determines foam lifetime. It is necessary to study this field, especially regarding drainage, with advances both in theory and experimentally. Drainage of foams has been extensively studied $[13,14]$. The liquid drainage along the Plateau borders leads to the increase in the capillary pressure, resulting in the formation of internal holes in the foam body. The film drainage theory can be described by the StefanReynolds equation [15] as

$$
V_{\mathrm{Re}}=\frac{2 h^{3}}{3 \mu R^{2}}\left(P_{\sigma}-\Pi\right)
$$

where $V_{\mathrm{Re}}$ describes the velocity of drainage, $h$ is the film thickness, $\mu$ is the liquid viscosity, $R$ is the film radius, and $P_{\sigma}$ and $\Pi$ are the capillary and disjoining pressures, respectively. Equation (3) indicates that the velocity of foam drainage depends not only on the hydrodynamic parameters of the foam system, such as the shape and size of the Plateau borders and gas/liquid interface properties, but also on the rate of internal foam destruction by the bubble coalescence.

So we present the schematic of the main mechanisms of foam stabilization in the fly ash and cement particles + SDS systems in Figure 5. The foam films were stabilized by adsorbed surfactant molecules and particles. Surfactant adsorption is directly related to the zeta potential of the particles, which is related to the different mineralogical phases of the cement powder composition [16]. Furthermore, cement is reactive and its properties, in particular the ionic concentrations within the paste, evolve with time. The ionic composition of the solution has an effect on the adsorption and zeta potential because of the effects of charge screening $[17,18]$. The gelled 3D network of particles in the Plateau borders and nodes created a yield stress and thus stabilized the foam with respect to water drainage and bubble Ostwald

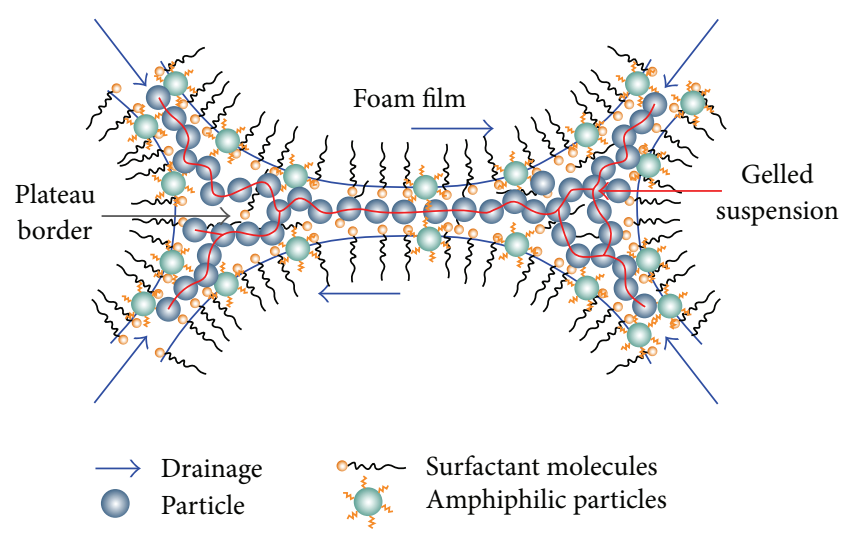

FIGURE 5: Schematic presentation of the main mechanisms of foam stabilization.

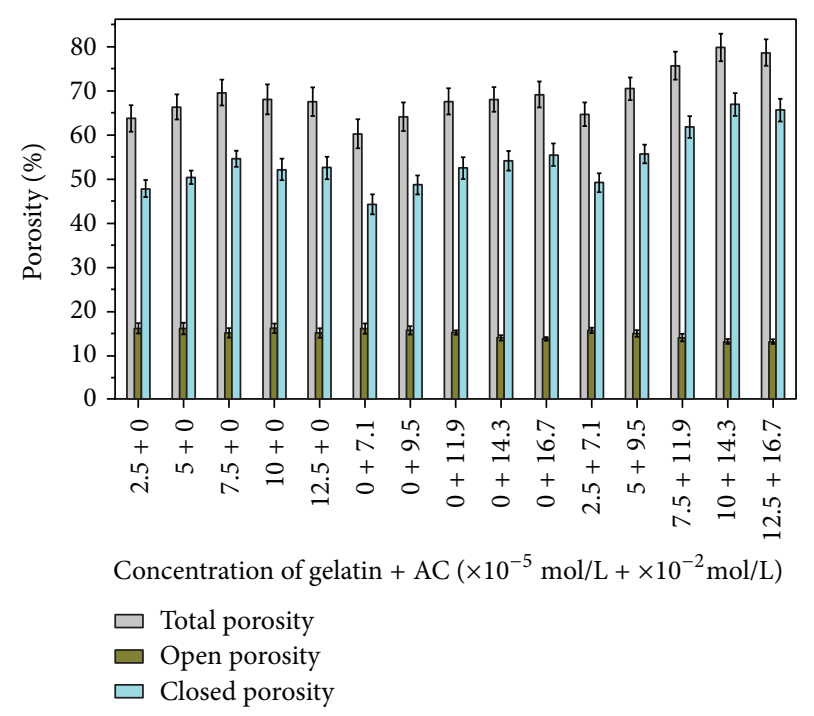

FIGURE 6: Effects of gelatin and AC on porosity of solidified foam.

ripening. The main challenge of this method is to adsorb the particles on the interface. The adsorption of SDS on the particles changed their hydrophobicity and then the amphiphilic particles were able to attach to air bubbles [1921]. The second prerequisite is to keep a stabilized bubble during solidification. Indeed, a solid thin film and then a closed bubble are obtained only if the hydration reaction occurs within the thin film covering the bubble: the film needs to be filled with particles but it also requires a sufficient quantity of water for the hydration reaction to occur. Moreover, the reaction adds new destabilization factors to the foam because of water movement, modification of particle properties, cement reactivity, and shrinkage.

After the water evaporated out, the fly ash and cement particles replicated the shape of bubbles to form the solidified foams, and hydration products piled up between the bubbles to form dense struts. During this process, if the pore wall was able to coagulate and hydrate quickly, the liquid could not carry the fly ash and cement particles to the Plateau borders and thus left the hole. It can be inferred that equilibriums 


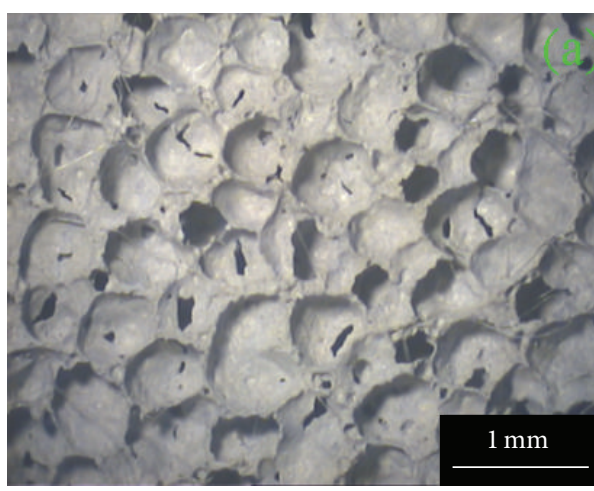

(a)

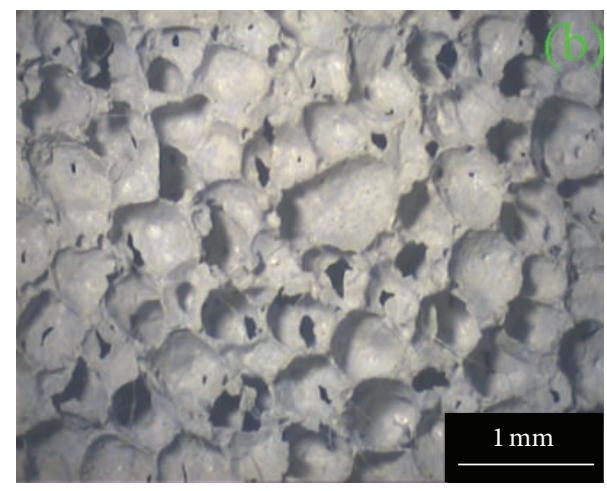

(b)

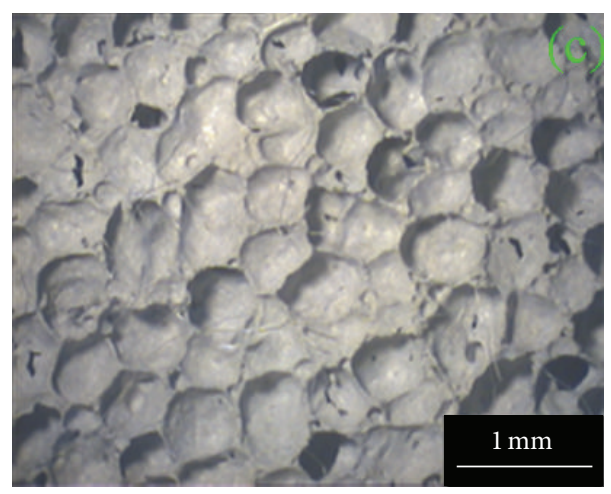

(c)

Figure 7: Optical images of (a) $7.4 \times 10^{-3} \mathrm{~mol} / \mathrm{L}$ SDS $+7.5 \times 10^{-5} \mathrm{~mol} / \mathrm{L}$ gelatin, (b) $7.4 \times 10^{-3} \mathrm{~mol} / \mathrm{L} \mathrm{SDS}+16.7 \times 10^{-2} \mathrm{~mol} / \mathrm{L} \mathrm{AC}$, and $(\mathrm{c}) 7.4 \times$ $10^{-3} \mathrm{~mol} / \mathrm{L} \mathrm{SDS}+10 \times 10^{-5} \mathrm{~mol} / \mathrm{L}$ gelatin $+14.3 \times 10^{-2} \mathrm{~mol} / \mathrm{L} \mathrm{AC}$.

between the hydration process and the drainage process may exist. Figure 3(f) demonstrates the characteristic of a hole in the pore wall, around which were seen the successive hydration products.

3.3. Foam Stabilizer and Setting Accelerator. The formation of ISF occurs in two stages: (i) production of fly and cement paste, foaming, and processing and (ii) maintaining foam stability until hardening. During the first phase, with homogeneous mixing of the aqueous foam and fly ash and cement slurry, workability is the determining factor for the specification of the fly ash and cement paste and their properties. A quick stabilization of the interface between air and fly ash and cement paste is essential. This can be managed by surfactants, a foam generator, and a mixer. In the second phase, the focus is on foam stability. Therefore, the separation of air and cement paste by bubble-up or flow-out methods has to be reduced to a minimum. This can be achieved by using accelerators, which stop collapse of the foam by rapid solidification. Gelatin, a kind of protein foam stabilizer, and AC, which can accelerate hydration and condensation of fly ash and cement particles, were added to the foam slurry based on the optimized concentration $\left(7.4 \times 10^{-3} \mathrm{~mol} / \mathrm{L}\right)$ of SDS. The corresponding porosities of the solidified foams are presented in Figure 6. To better understand the reason for the porosity changes as a function of the gelatin and $\mathrm{AC}$, three samples with different stabilization systems-SDS + gelatin,

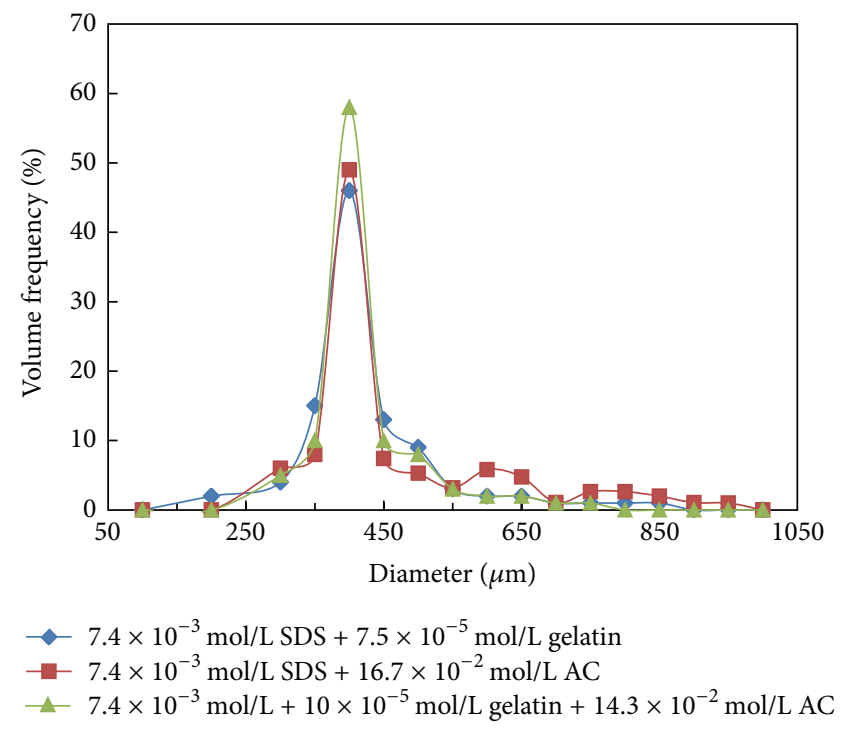

FIGURE 8: Effect of gelatin and AC on bubble-size distribution.

$\mathrm{SDS}+\mathrm{AC}$, and $\mathrm{SDS}+$ gelatin $+\mathrm{AC}$ in their best concentrations-were observed by a digital polarizing microscope equipped with morphological analysis software, as shown in Figure 7. 


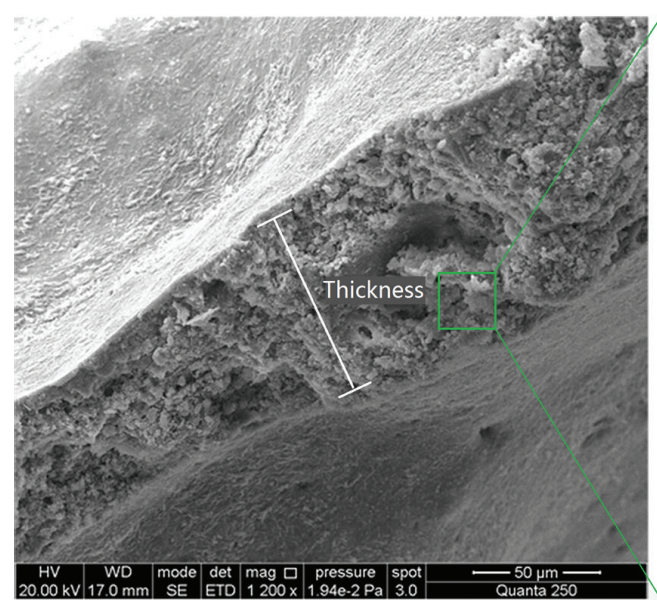

(a)

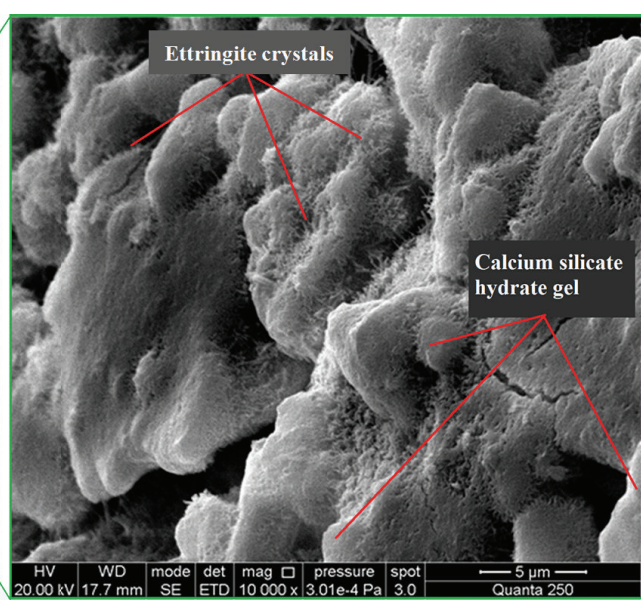

(b)

FIGURE 9: SEM micrograph of the solidified bubble wall obtained with $7.4 \times 10^{-3} \mathrm{~mol} / \mathrm{L} \mathrm{SDS}+10 \times 10^{-5} \mathrm{~mol} / \mathrm{L}$ gelatin $+14.3 \times 10^{-2} \mathrm{~mol} / \mathrm{L} \mathrm{AC}$.

With the presence of gelatin and $\mathrm{AC}$, the porosity of solidified foam was higher than that of foam obtained in former experiments. As the concentration of gelatin was increased from $2.5 \times 10^{-5} \mathrm{~mol} / \mathrm{L}$ to $12.5 \times 10^{-5} \mathrm{~mol} / \mathrm{L}$, the total and closed porosity firstly increased and then decreased and the open porosity fluctuated between $15 \%$ and $16 \%$, while the maximal closed porosity reached a maximum of $54.55 \%$ at $7.5 \times 10^{-5} \mathrm{~mol} / \mathrm{L}$ gelatin concentration. From Figure 8, the bubble diameters were $350-400 \mu \mathrm{m}$ with a volume frequency of $46 \%$, values that are higher than those of the individual SDS stabilization system, which had a volume frequency of $41 \%$. This shows that the bubble-size distribution is more uniform. This fact can be explained as follows: gelatin can increase the viscosity of the continuous phase of the foam, which leads to lower gravitational drainage and lower bubble coalescence, resulting in higher foam stability. Moreover, it is known that gelatin can form a viscoelastic film around air cells via noncovalent intermolecular interactions and covalent intermolecular disulphide cross-linking, which also results in an increased stability above a threshold concentration. Besides, surfactant mixtures (SDS + gelatin) could create a mixed surfactant layer at gas/liquid interfaces. When two bubbles approach each other to form a thin liquid film, this mixed surfactant layer can alter the disjoining pressure in the films by changing the surface potential, modified the capillary force and the boundary conditions governing the drainage process, and increased resistance to perturbations that could lead to film rupture and thus contributed to a more stable foam with higher closed porosity. Based on the outstanding foam stability resulting from synergistic effects, the microstructure of samples consisted mainly of closed pores, as shown in Figure 7(a). The stability and rheological properties of foam and emulsion films stabilized by gelatinsurfactant complexes were described first by Derkatch, Skurtys, and Aguilera [22-24], who reported that films are either stable or unstable depending on the content of the stabilizing complex. However, too much gelatin increased the weight of the pore walls and slightly reduced the total porosity and closed porosity.
In addition, Figure 6 shows that the total porosity and closed porosity increased continuously as the AC increased, with the maximal values of $69.11 \%$ and $55.46 \%$, respectively, at $16.7 \times 10^{-2} \mathrm{~mol} / \mathrm{L}$ AC concentration, as shown in Figure 7(b). As shown in Figure 8, the bubble diameter was $350-400 \mu \mathrm{m}$ with a volume frequency of $49 \%$, which is also higher than the individual SDS stabilization system and the SDS + gelatin system with volume frequencies of $41 \%$ and $46 \%$, respectively. This shows that the bubble-size distribution is more uniform. These results may be because the AC accelerated the hydration process and the pore wall coagulated before the end of drainage. When $\mathrm{C}_{11} \mathrm{~A}_{7} \cdot \mathrm{CaF}_{2}$ is added to an inorganic solidified foam system, $\mathrm{Al}_{2} \mathrm{O}_{3}$, coming from the admixture, could react with gypsum to immediately form ettringite crystals (AFt), which will adhere to the particle surface [25]. At the same time, the consumption of gypsum accelerates the rate of tricalcium silicate $\left(\mathrm{C}_{3} \mathrm{~S}\right)$ hydration, forming a small amount of fibrous $\mathrm{CSH}$ filling among the cement particles [26].

More importantly, the systems with a mixture of gelatin and $\mathrm{AC}$ functioned more efficiently than the individual gelatin or AC systems in improving the total porosity and closed porosity. When the concentrations of gelatin and $\mathrm{AC}$ were $10 \times 10^{-5} \mathrm{~mol} / \mathrm{L}$ and $14.3 \times 10^{-2} \mathrm{~mol} / \mathrm{L}$, respectively, the solidified foam (Figure $7(\mathrm{c})$ ) had the maximum and optimized total porosity and closed porosity, reaching values of $79.89 \%$ and $66.89 \%$, respectively. As shown in Figure 8, the bubble diameter is $350-400 \mu \mathrm{m}$ with a volume frequency of $58 \%$, which is higher than the individual SDS stabilization system, the SDS + gelatin system, and the SDS + AC system, which have volume frequencies of $41 \%, 46 \%$, and $49 \%$, respectively. This shows that the bubble-size distribution is the best in our experiments. The solid bubbles obtained with a system consisting of $7.4 \times 10^{-3} \mathrm{~mol} / \mathrm{L}$ SDS $+10 \times 10^{-5} \mathrm{~mol} / \mathrm{L}$ gelatin $+14.3 \times 10^{-2} \mathrm{~mol} / \mathrm{L}$ AC were observed by scanning electronic microscopy. Figure 9(a) shows that the solid film has a thickness of $50 \pm 5 \mu \mathrm{m}$. Therefore, the liquid film after drainage is filled with homogeneously distributed particle 
multilayers. At a larger magnification shown in Figure 9(b), fly ash and cement grains can be observed mixed with the hydrated phase $(\mathrm{CSH})$ and a large amount of hydration products compactly accumulated on the pore wall. These $\mathrm{CSH}$ phases indicate that, during the process, the liquid film retains a sufficient amount of liquid to allow the hydration reaction to occur within the protective layer.

\section{Conclusions}

(1) A solidified foam for preventing coal fires was produced with a closed porosity of $66.89 \%$ and bubble diameters of 350-400 $\mu \mathrm{m}$ with a volume frequency of $58 \%$ from an SDS/gelatin/AC foamed and stabilized system.

(2) During the individual SDS foaming, at approximately the CMC, it could be clearly seen that the pores were still partly closed, which was attributed to the gravitational drainage. The mean pore size increased and the space between the pores (cell wall thickness) began to decrease. Based on observation of the microstructure of the open pore after solidification, the stabilization mechanism of the pore wall was proposed based on the result from the equilibrium between the hydration process and the drainage process.

(3) Gelatin increased the viscosity of the continuous phase of the foam to form a viscoelastic film around the air cells, and the surfactant mixtures (SDS + gelatin) created a mixed surfactant layer at gas/liquid interfaces. All above effects led to a lower gravitational drainage and lower bubble coalescence, resulting in higher foam stability. Also, AC accelerated the hydration process and the pore walls coagulated before the end of drainage based on observation that showed that the liquid film after drainage was filled with homogeneously distributed particle multilayers. Of these, the mixed SDS + gelatin + AC systems produced both good total porosity and high closed porosity, which verified the proposed stabilization mechanism.

\section{Conflict of Interests}

The authors declare that there is no conflict of interests regarding the publication of this paper.

\section{Acknowledgments}

This work was supported by the National Natural Science Foundation of China (U1361213, 51476184), the Priority Academic Program Development of Jiangsu Higher Education Institutions, and the Fundamental Research Funds for the Central Universities (CUMT, 2014ZDPY24).

\section{References}

[1] G. B. Stracher and T. P. Taylor, "Coal fires burning out of control around the world: thermodynamic recipe for environmental catastrophe," International Journal of Coal Geology, vol. 59, no. 1-2, pp. 7-17, 2004.

[2] B. T. Qin and Y. Lu, "Experimental research on inorganic solidified foam for sealing air leakage in coal mines," International Journal of Mining Science and Technology, vol. 23, no. 1, pp. 151155, 2013.

[3] M. Tan Hoang and C. Perrot, "Solid films and transports in cellular foams," Journal of Applied Physics, vol. 112, no. 5, Article ID 054911, 2012.

[4] B. G. Han, Z. X. Yang, X. M. Shi, and X. Yu, "Transport properties of carbon-nanotube/cement composites," Journal of Materials Engineering and Performance, vol. 22, no. 1, pp. 184-189, 2013.

[5] X. N. Liu, Y. X. Li, X. Chen, Y. Liu, and X. L. Fan, "Foam stability in gas injection foaming process," Journal of Materials Science, vol. 45, no. 23, pp. 6481-6493, 2010.

[6] F. Krauss Juillerat, U. T. Gonzenbach, P. Elser, A. R. Studart, and L. J. Gauckler, "Microstructural control of self-setting particlestabilized ceramic foams," Journal of the American Ceramic Society, vol. 94, no. 1, pp. 77-83, 2011.

[7] B. Qin, Y. Lu, F. Li, Y. Jia, C. Zhu, and Q. Shi, "Preparation and stability of inorganic solidified foam for preventing coal fires," Advances in Materials Science and Engineering, vol. 2014, Article ID 347386, 10 pages, 2014.

[8] P. Petit, I. Javierre, P. H. Jézéquel, and A.-L. Biance, "Generation and stability of bubbles in a cement based slurry," Cement and Concrete Research, vol. 60, pp. 37-44, 2014.

[9] R. D. Moser, P. G. Allison, and M. Q. Chandler, "Characterization of impact damage in ultra-high performance concrete using spatially correlated nanoindentation/SEM/EDX," Journal of Materials Engineering and Performance, vol. 22, no. 12, pp. 3902-3908, 2013.

[10] Standardization Administration of the People's Republic of China, "Standard test method for cement density," GB/T2081994, Standardization Administration of the People's Republic of China, Beijing, China, 1994.

[11] S. E. Anachkov, K. D. Danov, E. S. Basheva, P. A. Kralchevsky, and K. P. Ananthapadmanabhan, "Determination of the aggregation number and charge of ionic surfactant micelles from the stepwise thinning of foam films," Advances in Colloid and Interface Science, vol. 183-184, pp. 55-67, 2012.

[12] M. Wang, H. Du, A. Guo, R. Hao, and Z. Hou, "Microstructure control in ceramic foams via mixed cationic/anionic surfactant," Materials Letters, vol. 88, pp. 97-100, 2012.

[13] S. A. Koehler, S. Hilgenfeldt, and H. A. Stone, "Generalized view of foam drainage: experiment and theory," Langmuir, vol. 16, no. 15, pp. 6327-6341, 2000.

[14] A. Saint-Jalmes, Y. Zhang, and D. Langevin, "Quantitative description of foam drainage: transitions with surface mobility," European Physical Journal E, vol. 15, no. 1, pp. 53-60, 2004.

[15] A. Sheludko, "Thin liquid films," Advances in Colloid and Interface Science, vol. 1, no. 4, pp. 391-464, 1967.

[16] A. Zingg, F. Winnefeld, L. Holzer, J. Pakusch, S. Becker, and L. Gauckler, "Adsorption of polyelectrolytes and its influence on the rheology, zeta potential, and microstructure of various cement and hydrate phases," Journal of Colloid and Interface Science, vol. 323, no. 2, pp. 301-312, 2008.

[17] Y. F. Houst, P. Bowen, F. Perche et al., "Design and function of novel superplasticizers for more durable high performance concrete (superplast project)," Cement and Concrete Research, vol. 38, no. 10, pp. 1197-1209, 2008. 
[18] L. Ferrari, J. Kaufmann, F. Winnefeld, and J. Plank, "Multimethod approach to study influence of superplasticizers on cement suspensions," Cement and Concrete Research, vol. 41, no. 10, pp. 1058-1066, 2011.

[19] Q. Liu, S. Zhang, D. Sun, and J. Xu, "Aqueous foams stabilized by hexylamine-modified Laponite particles," Colloids and Surfaces A: Physicochemical and Engineering Aspects, vol. 338, no. 1-3, pp. 40-46, 2009.

[20] L. R. Arriaga, W. Drenckhan, A. Salonen et al., "On the longterm stability of foams stabilised by mixtures of nano-particles and oppositely charged short chain surfactants," Soft Matter, vol. 8, no. 43, pp. 11085-11097, 2012.

[21] Z. G. Cui, Y. Z. Cui, C. F. Cui, Z. Chen, and B. P. Binks, "Aqueous foams stabilized by in situ surface activation of $\mathrm{CaCO}_{3}$ nanoparticles via adsorption of anionic surfactant," Langmuir, vol. 26, no. 15, pp. 12567-12574, 2010.

[22] S. R. Derkatch, L. A. Petrova, V. N. Izmailova, and B. N. Tarasevitch, "Properties of emulsion films made from binary aqueous mixtures of gelatin-surfactant: the effect of concentration and $\mathrm{pH}$, " Colloids and Surfaces A: Physicochemical and Engineering Aspects, vol. 152, no. 1-2, pp. 189-197, 1999.

[23] S. R. Derkach, "Interfacial layers of complex-forming ionic surfactants with gelatin," Journal of Colloid Interface Science, 2014.

[24] O. Skurtys and J. M. Aguilera, "Structuring bubbles and foams in gelatine solutions within a circular microchannel device," Journal of Colloid and Interface Science, vol. 318, no. 2, pp. 380388,2008

[25] F. Qiao, C. K. Chau, and Z. Li, "Setting and strength development of magnesium phosphate cement paste," Advances in Cement Research, vol. 21, no. 4, pp. 175-180, 2009.

[26] Z. Huan, J. Chang, and J. Zhou, "Low-temperature fabrication of macroporous scaffolds through foaming and hydration of tricalcium silicate paste and their bioactivity," Journal of Materials Science, vol. 45, no. 4, pp. 961-968, 2010. 

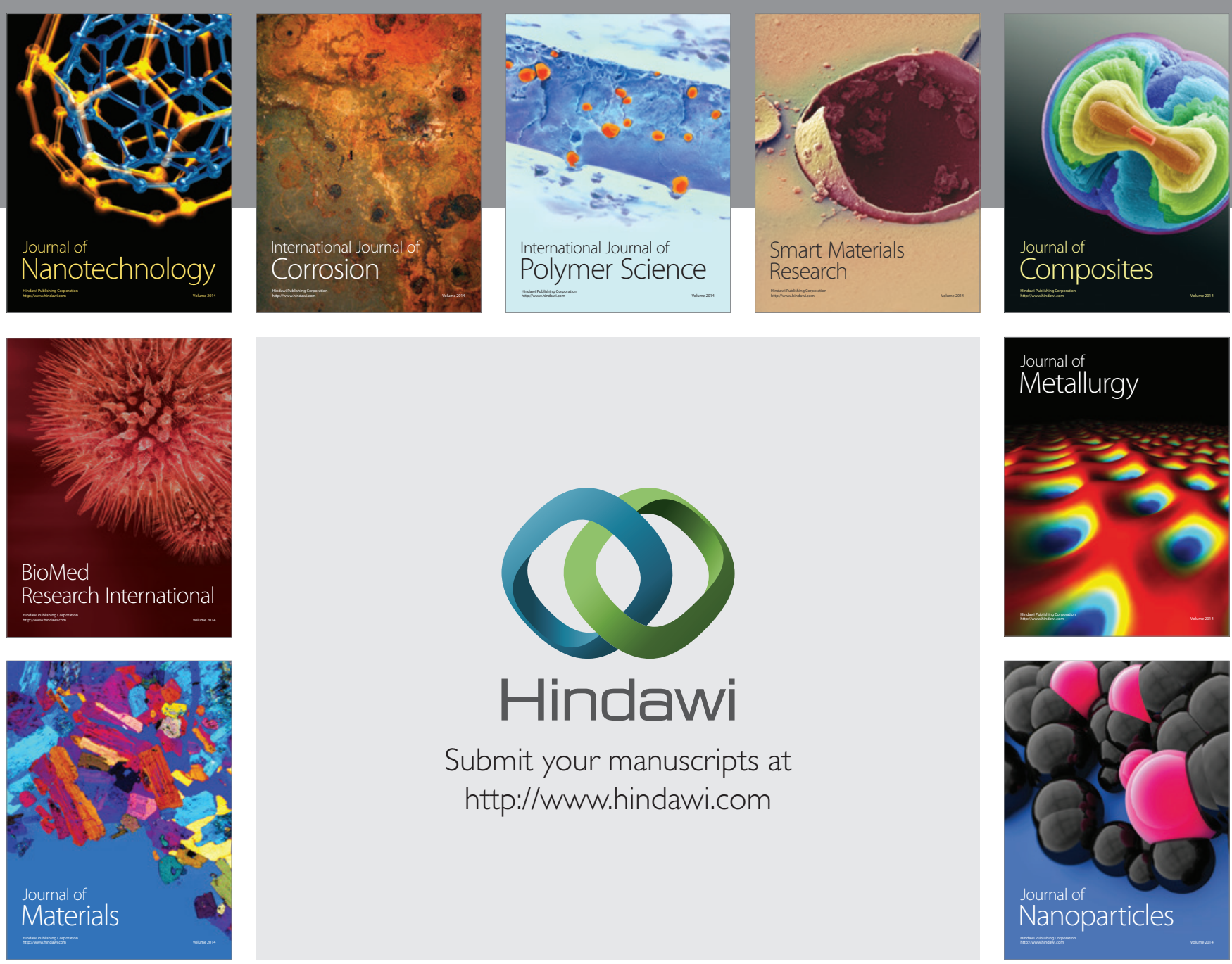

Submit your manuscripts at http://www.hindawi.com
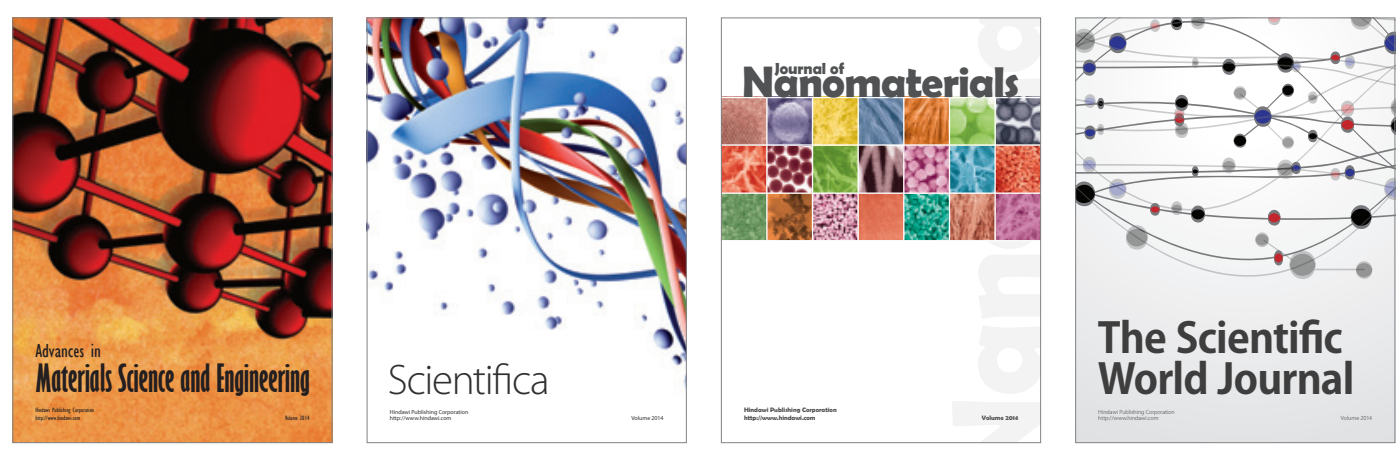

\section{The Scientific World Journal}
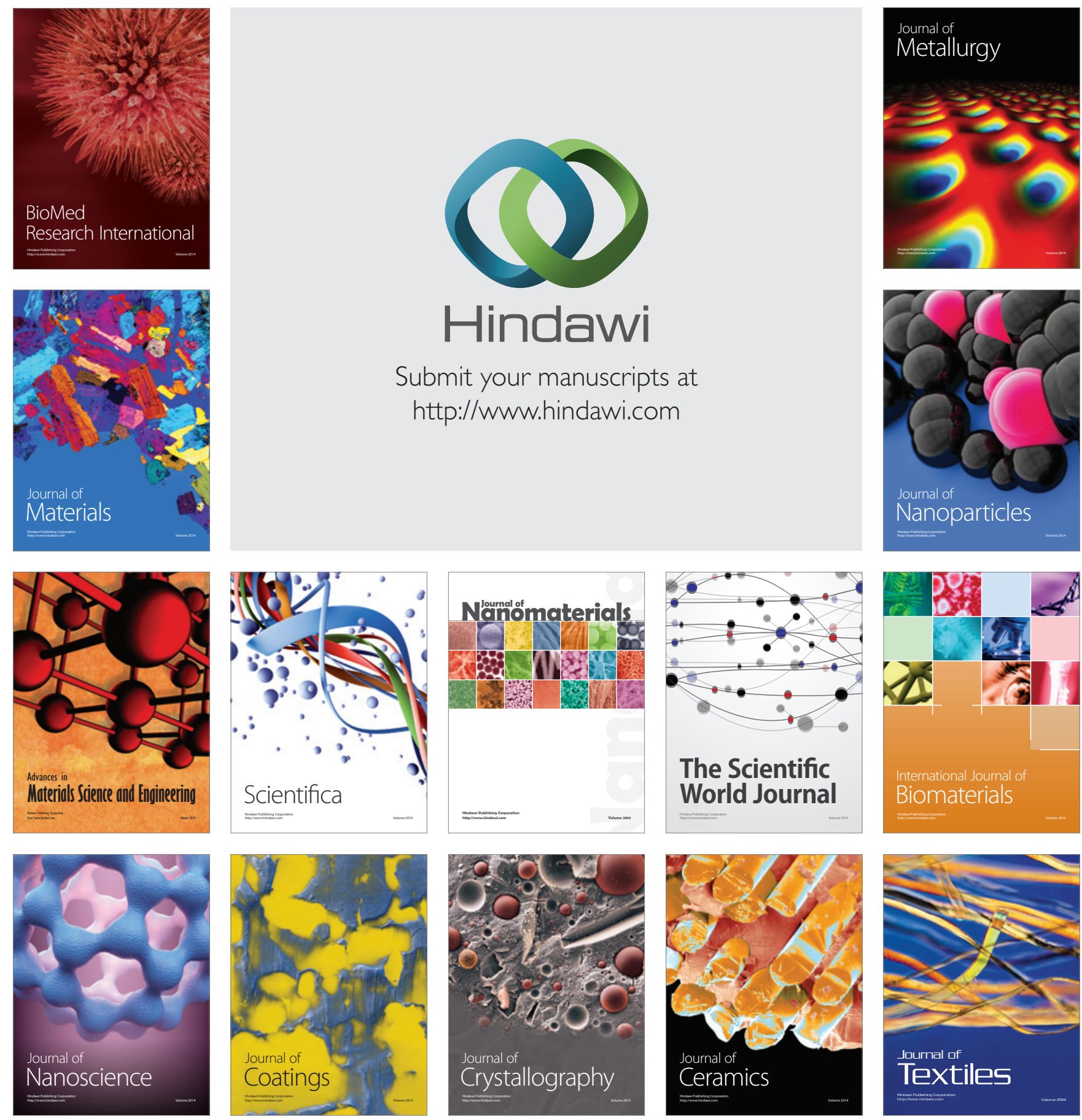